\title{
ELABORACIÓN DE NÓDULOS EN PORCELANA PARA EXPERIMENTOS DE TALLA LÍTICA ${ }^{13}$
}

\author{
Making porcelain nodules for knapping experiments
}

Nuria Castañeda Clemente ${ }^{14}$

\section{Resumen:}

Se presentan los resultados de una experiencia piloto sobre la fabricación de nódulos de porcelana con dos tipos de masa diferentes y varios colores. La experiencia tiene dos objetivos de cara a futuros programas experimentales. El primero es escoger la calidad de la masa porcelánica en función de su respuesta a la talla con varios percutores. El segundo objetivo es probar la visibilidad de los estigmas de talla en diferentes colores. Un tercer objetivo que subyace en este trabajo es adquirir la competencia en la fabricación de estos nódulos, buscando el autoabastecimiento del Laboratorio de Arqueología Experimental.

Palabras clave: materias primas, porcelana, talla lítica.

\begin{abstract}
:
This work presents the results of a controlled experience on porcelain nodules manufacture using two types of porcelain clay and different colours. The experience has two main objectives in order to carry out future experimental programs. The first goal is to compare and choose which type of clay offers better results on knapping with different hammers. The second objective is to test the visibility of knapping stigmas in different colours. A third objective that underlies this experience is to reach the Experimental Archaeology Laboratory self-sufficiency by acquiring the skill of porcelain nodules manufacture.
\end{abstract}

Keywords: raw materials, porcelain, lithic knapping.

\section{INTRODUCCIÓN Y OBJETIVOS}

Realizar programas experimentales con rocas silíceas requiere de una gran cantidad de materia prima que, en ocasiones es difícil de encontrar y se corre el riesgo de diezmar (Khreisheh et al. 2013). Utilizar la misma materia prima que los casos arqueológicos que se quieren explicar, suele ser una variable crucial para garantizar una misma respuesta mecánica en determinados experimentos. Sin embargo, cuando se requiere el control de algunas variables y la materia prima no es fundamental en los resultados, puede recurrirse a materiales industriales (p. ej. Crabtree 1971: 22; Speth 1972: 38; Dibble y Whittaker 1981: 284; Davis y Shea 1988: 604; Baena y González 1998:19; Whittaker 1994; Dibble y Pelcin 1995: 429; Whittaker y Stafford 1999; Geribàs et al. . 2010; Harwood y Crandell 2010; Khreisheh et al. 2013). En ejemplos etnográficos se ha observado la utilización de materiales industriales como el vidrio o la porcelana para realizar las herramientas

\footnotetext{
${ }^{13}$ Recibido: 15/03/2019. Aceptado: 08/05/2019. http://doi.org/10.15366/baexuam2018-19.13.004

${ }^{14}$ Universidad Autónoma de Madrid. ORCID: 0000-0001-6563-5750. E-mail: nuria.castanneda@uam.es
} 
necesarias ya que sus propiedades mecánicas son similares a las de algunas rocas silíceas (p. ej. Roy 2009; Cotterell 2010: 95-96): tiene fractura concoidea y predecible.

Además, la porcelana en concreto tiene ventajas sobre otros materiales como por ejemplo el escaso coste económico y la propiedad de poderse modelar o replicar en moldes para conseguir soportes homogéneos (Khreisheh et al. 2013).

El objetivo de este trabajo es desarrollar un protocolo para la fabricación de nódulos de porcelana que permitan el abastecimiento de materia prima de futuros programas experimentales en los que no se requiera un tipo de material silíceo concreto. Estos nódulos ya se emplean en experimentaciones y suelen ser encargados a ceramistas (p. ej. Khreisheh et al. 2013). En el Laboratorio de Arqueología Experimental de la Universidad Autónoma de Madrid se cuenta con los medios materiales para poder llevar a cabo esta fabricación.

El proceso de trabajo que se describe en esta experiencia piloto consiste en elaborar cuatro nódulos de porcelana, utilizando dos tipos de masa existentes en el mercado y colores claros y oscuros para poder valorar su efectividad ante diferentes técnicas de talla y la visibilidad de los estigmas.

\section{METODOLOGÍA}

Como punto de partida, se han escogido dos tipos de masa: porcelana SAF (temperatura de cocción $980^{\circ}$, gresificación a $1280^{\circ}$ ) en colores amarillo y negro y arcilla porcelánica TecniClay (gresificado a $980-1020^{\circ}$ ) en colores amarillo y azul. Aparte de las diferencias en la temperatura de gresificación, la porcelana TecniClay incluye mucha más cantidad de agua que la SAF, lo cual tendrá consecuencias en el cálculo de la masa inicial necesaria para otros experimentos.

La elección de los colores se debe a la necesidad de comprobar la visibilidad de los atributos en colores claros u oscuros. La porcelana blanca no se tuvo en cuenta en comparación con experiencias de análisis sobre sílex de color blanco en el que tanto extracciones muy planas, como huellas de impacto, son muy difíciles de apreciar. Además de las dificultades que presentan, por ejemplo, ante la fotografía.

Se han elaborado cuatro nódulos con un peso inicial de masa de porcelana de 1 k (Fig. 1). Se ha escogido modelarlos en forma de riñones oblongos que faciliten una talla bifacial, determinado por el tipo de experimentos que se realizarán en próximos programas experimentales. La primera observación indica que el peso de $1 \mathrm{k}$ en húmedo es insuficiente para llevar a cabo muchas de las reducciones líticas que se pretenden realizar en un futuro como bifaces o hachas, teniendo en cuenta que, en el proceso, los nódulos perderán como mínimo, el peso del agua que contienen. 

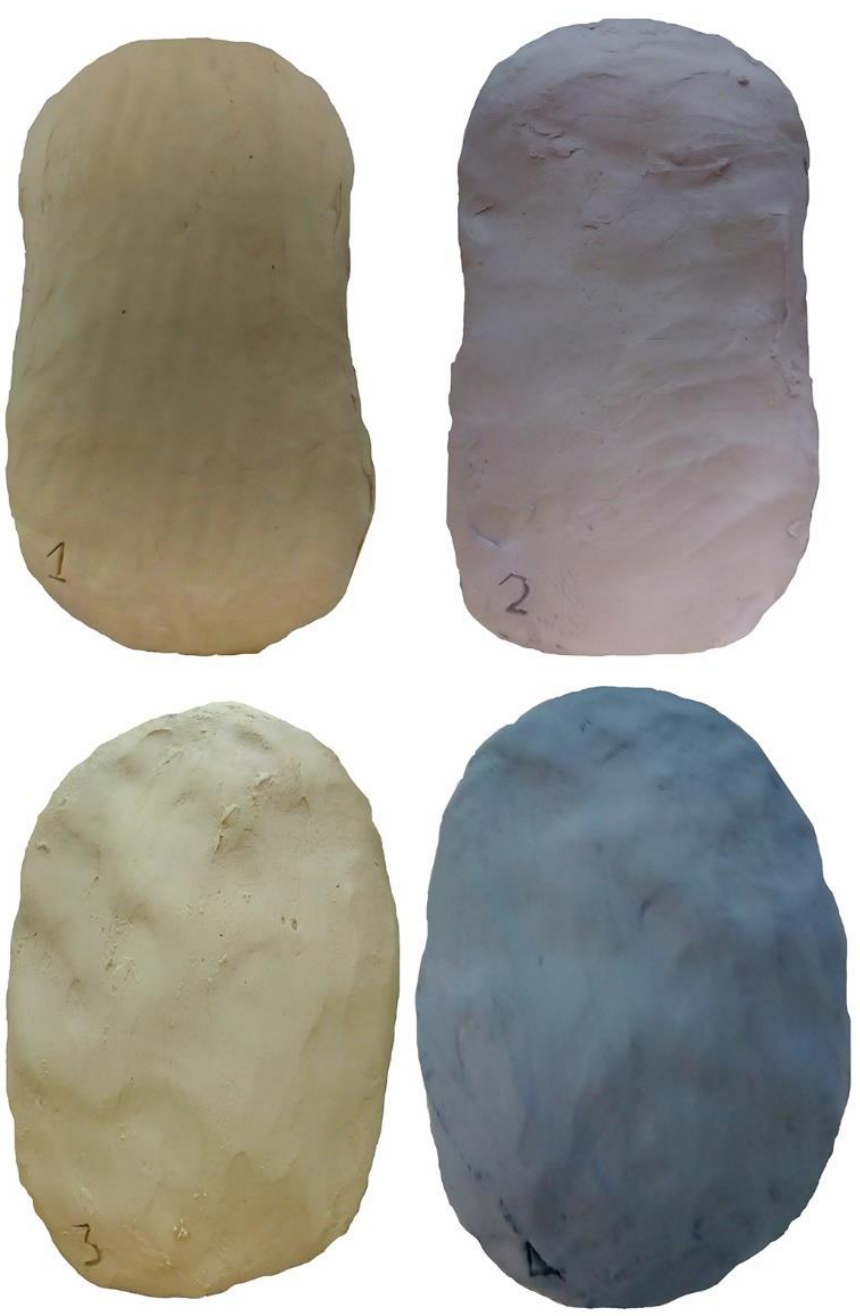

Figura 4: aspecto de los nódulos modelados en crudo.

Los cuatro nódulos se mantuvieron en el proceso de secado, en interior a temperatura constante, durante 20 días. Tras este proceso se midieron y pesaron, constatando una pérdida de agua diferencial según los dos tipos de masa. Las arcillas TecniClay perdieron un $27-28 \%$, mientras que los nódulos de porcelana SAF perdieron un $26,2 \%$ y un $24 \%$ respectivamente (Tabla 1 ). 


\begin{tabular}{|c|c|c|c|c|c|c|}
\hline Nódulos & Masa & Color & $\begin{array}{l}\text { Dimensiones } \\
(\mathrm{mm})\end{array}$ & $\begin{array}{l}\text { Peso } \\
\text { húmedo } \\
(\mathrm{g})\end{array}$ & $\begin{array}{l}\text { Peso } \\
\text { seco } \\
(\mathrm{g})\end{array}$ & Peso cocido (g) \\
\hline 1 & Tecniclay & Amarillo & 170x97x38 & 1000 & 724 & $\begin{array}{l}606 \mathrm{~g} \text { total; } 3 \\
\text { fragmentos } \\
\text { mayores pesan } 66, \\
92 \text { y } 116 \mathrm{~g}\end{array}$ \\
\hline 2 & Tecniclay & Azul & $182 \times 98 \times 34$ & 1000 & 720 & $\begin{array}{l}572 \mathrm{~g} \text { total; los } \\
\text { dos fragmentos } \\
\text { mayores pesan: } \\
124 \text { y } 354 \mathrm{~g} \mathrm{(480} \mathrm{g} \\
\text { juntos) }\end{array}$ \\
\hline 3 & SAF & Amarillo & $163 \times 107 \times 36$ & 1000 & 738 & $\begin{array}{l}632 \mathrm{~g} \text { total; el } \\
\text { fragmento mayor } \\
\text { pesa } 394 \mathrm{~g}\end{array}$ \\
\hline 4 & SAF & Negro & $174 \times 122 \times 29$ & 1000 & 760 & $\begin{array}{l}678 \text { total; el } \\
\text { fragmento mayor } \\
\text { pesa } 534 \mathrm{~g}\end{array}$ \\
\hline
\end{tabular}

Tabla 1: Datos de los nódulos: tipo de masa, color, dimensiones y pesos en las diferentes fases del proceso.

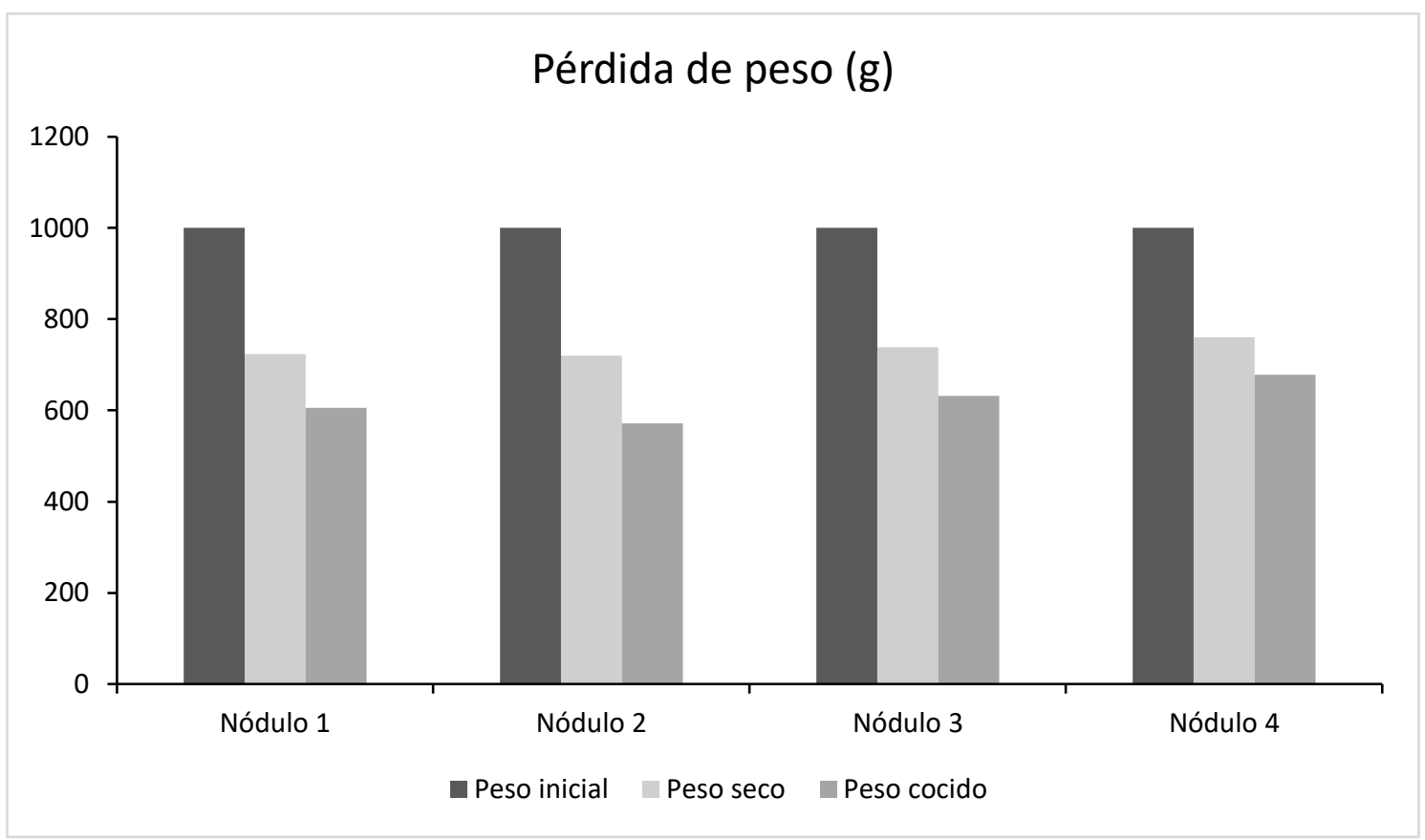

Figura 5: Gráfico de la pérdida de peso sufrida por los cuatro nódulos en las diferentes fases del proceso

En cuanto a la cocción, esta se realizó en el horno eléctrico del Laboratorio de Arqueología Experimental. Dadas los diferentes puntos de gresificación de las dos masas utilizadas y, teniendo en cuenta el límite de temperatura del horno $\left(1200^{\circ}\right)$ y que se 
buscaba la gresificación de los nódulos para obtener una textura lo más próxima posible a las rocas silíceas, se programó una curva de cocción que alcanzara los $1100^{\circ}$ y se mantuviera 15 minutos en esas condiciones (Fig. 3). El horno tardó 5 horas en alcanzar dicha temperatura y 24 horas en descender a temperatura ambiente.

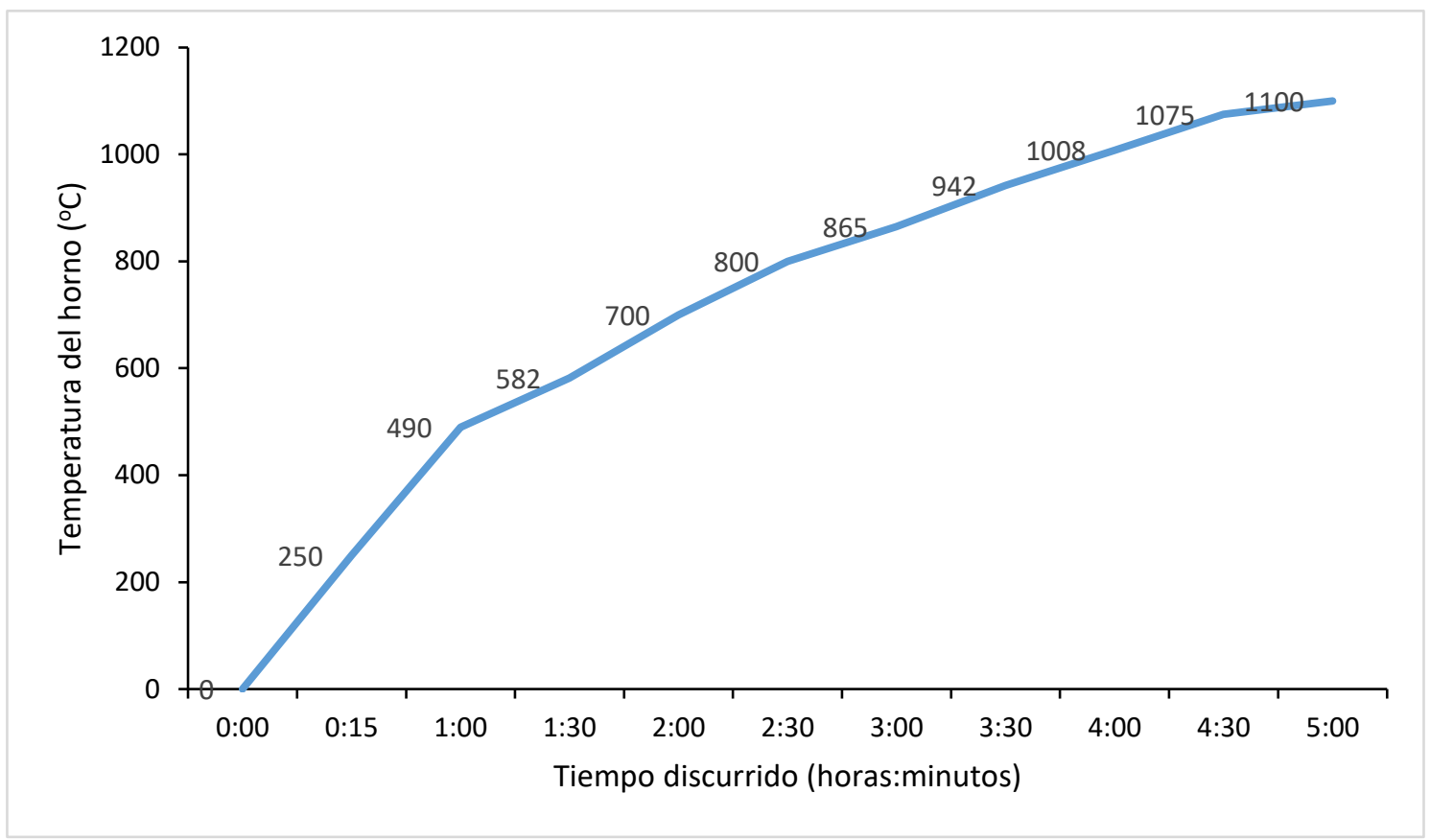

Figura 6: Curva de temperaturas del horno en la cocción de la porcelana. La curva de descenso duró 24 horas.

\section{RESULTADOS}

Defectos en el amasado produjeron la fragmentación de los nódulos por burbujas de aire existentes (Fig. 4) De lo que se desprende que el buen amasado es fundamental para el éxito de la cocción, como es lógico. Los nódulos de arcilla TecniClay llegaron a la gresificación con un aspecto vítreo al exterior en el caso del nódulo 1 y aspecto vítreo generalizado en el caso del nódulo 2 (Fayenza).

Se constata una dramática reducción de peso en todo el proceso, si obviamos el hecho de la fragmentación por la presencia de burbujas, el volumen inicial se ha reducido entre un $32,2 \%$ (nódulo 4) y un 42,8\% (nódulo 2). Esto indica que para garantizar un nódulo de peso final de $1000 \mathrm{~g}$ se debe utilizar un peso inicial de entre $1300 \mathrm{y} 1400 \mathrm{~g}$ de masa en húmedo. 


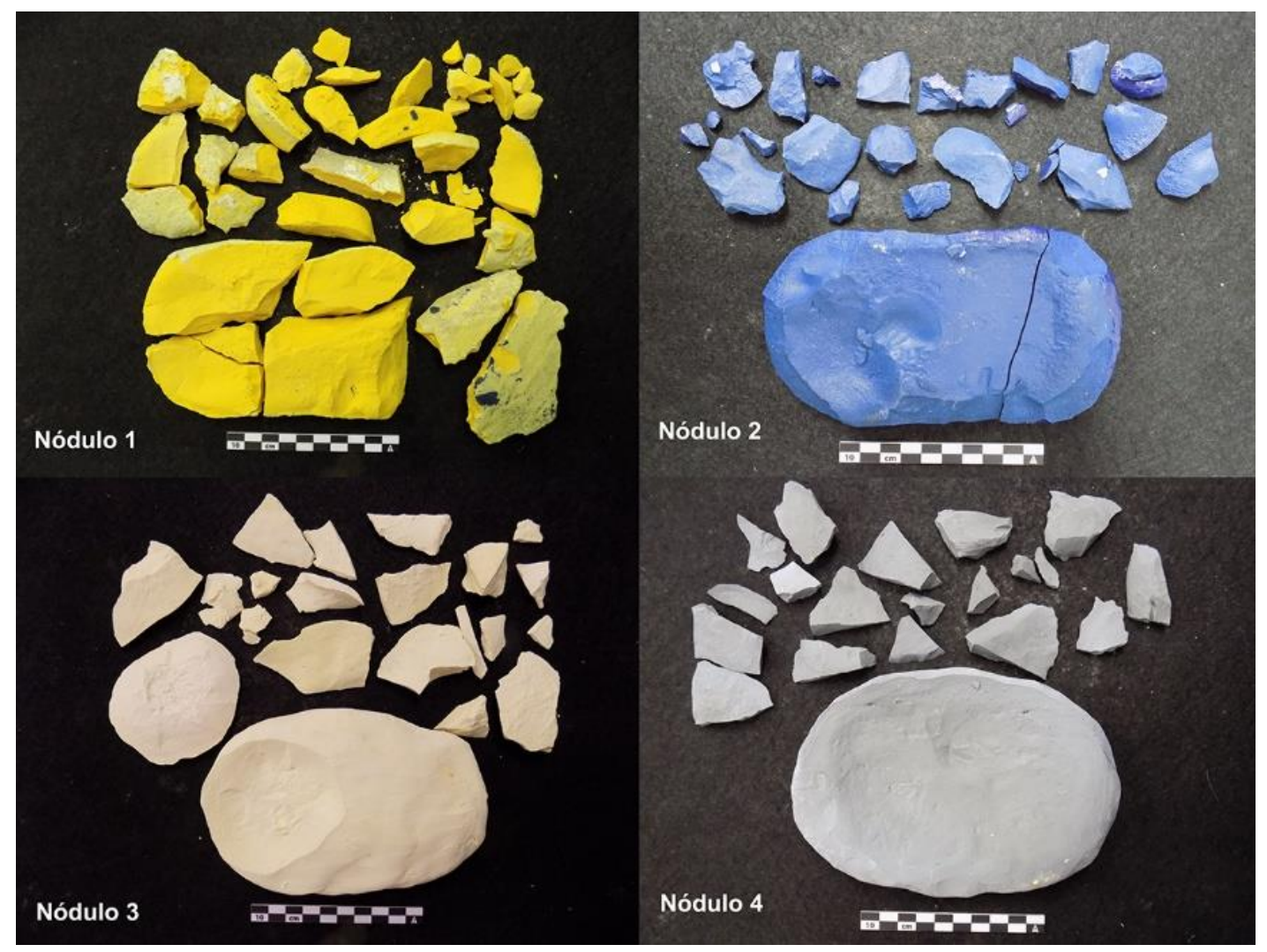

Figura 7: Aspecto de los cuatro nódulos una vez cocidos.

Como resultado del incidente durante la cocción, el experimento quedó un poco limitado sobre todo en el caso del nódulo 1, cuyo fragmento de mayor tamaño pesa $116 \mathrm{~g}$. En el resto de nódulos, la masa resultante es suficiente para probar con diferentes modalidades de percusión directa.

La experiencia se ha visto ampliamente beneficiada por la participación del Prof. Javier Baena que se ha ofrecido a probar la respuesta de los nódulos a los diferentes tipos de percusión.

\subsection{Prueba con percutor mineral (piedra dura):}

Los cuatro nódulos han ofrecido una respuesta positiva ante la percusión con cuarcita (Fig. 5). La distinción de atributos de distintas técnicas de talla no es el objetivo ni de este trabajo, ni de las futuras experiencias que lo han originado. No obstante, se ha podido observar con esta experiencia que las propiedades de la porcelana atenúan los atributos propios de la percusión con percutor mineral duro. Estos se asemejan a los producidos con percutores elásticos. En general, los conos de percusión no aparecen tan marcados, ni por supuesto, las ondas y los talones parecen más finos. 
En su valoración, el profesor Baena destaca la homogeneidad del material en general, no mostrando preferencias por ninguno de los nódulos. Si bien los nódulos 2 y 4 presentan un comportamiento más parecido entre sí.

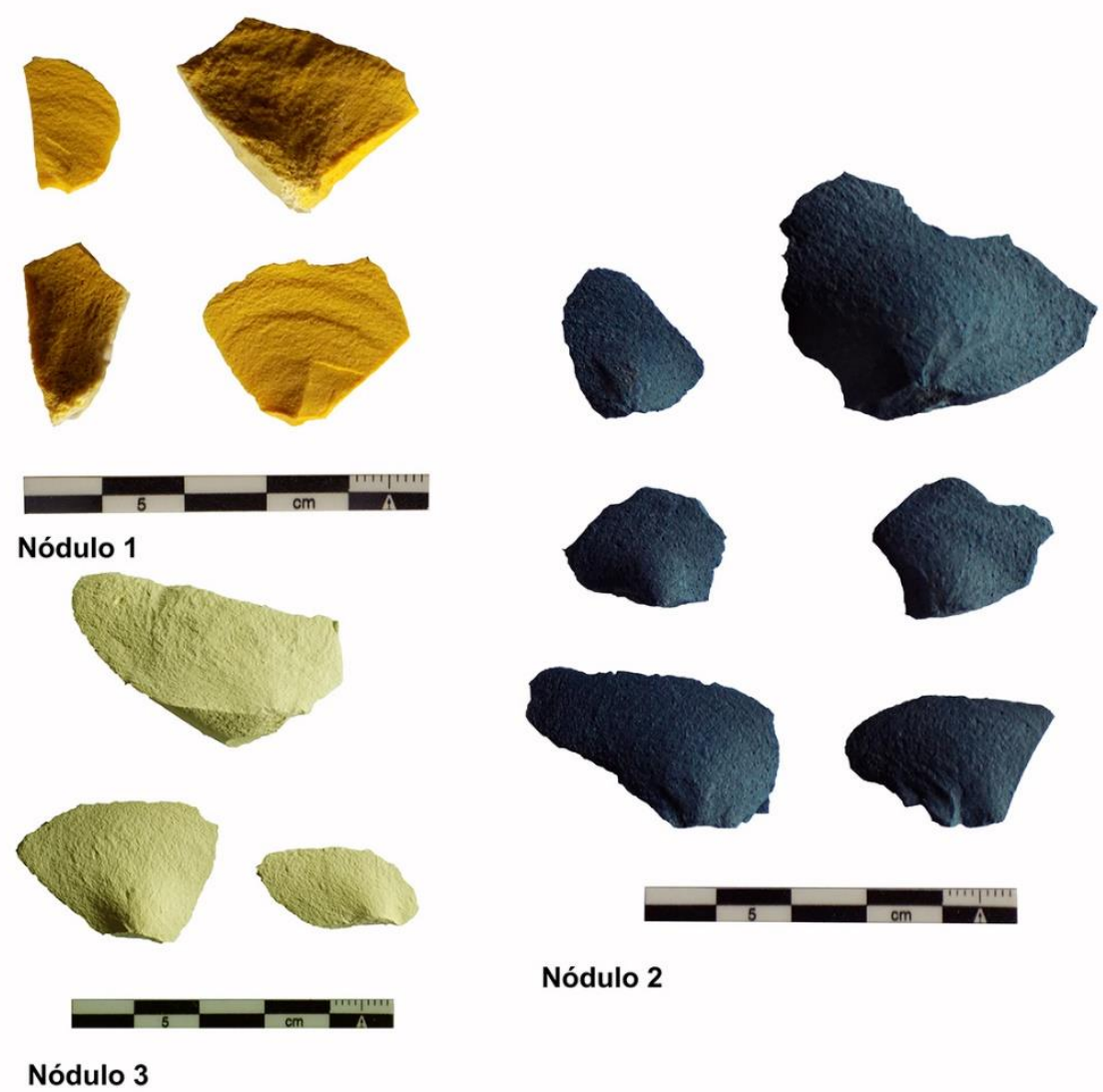

Figura 8: caras ventrales de los productos obtenidos con percutor de cuarcita.

\subsection{Pruebas con percutor mineral (piedra blanda):}

De la misma forma, los cuatro nódulos se han sometido a la percusión con percutor mineral de caliza, mostrando diferencias entre los diferentes nódulos.

Al margen de las dificultades propias del núcleo 1 que ha quedado muy mermado por la cocción, se observa una respuesta muy positiva para la laminación con golpe tangencial.

En cuanto al nódulo 3 presenta un comportamiento muy parecido a la caliza silicificada.

En este caso, el tallador prefiere claramente los nódulos 2 y 4, que presentan características similares.

De nuevo se observa que los atributos son muy similares a los de percutores orgánicos. 

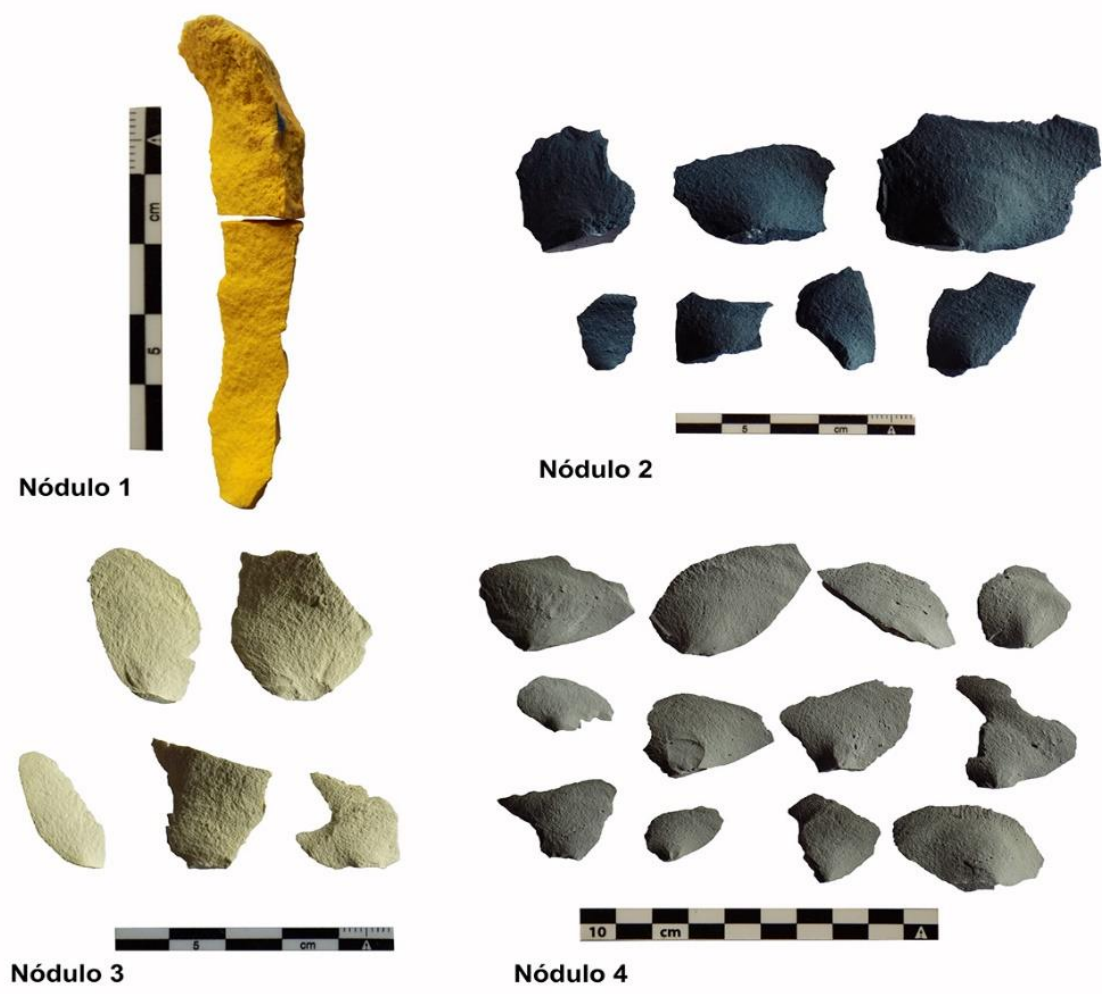

Nódulo 2

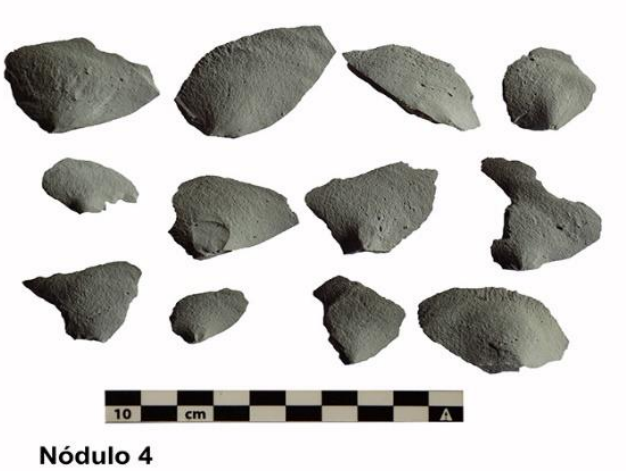

Figura 6: caras ventrales de los productos obtenidos con percutor de caliza.

\subsection{Pruebas con percutor orgánico (madera):}

Al probar los nódulos con percutor de boj, se observa una mayor tenacidad en los nódulos 2 y 4 (Fig. 7) y un buen resultado general, obteniéndose extracciones más invasoras y con alta frecuencia en la aparición de labios.

\subsection{Pruebas con percutor orgánico (asta):}

En general, la talla con percutor de asta ha sido la que mayores diferencias ha aportado (fig. 8). El nódulo 3 no permite una preparación por abrasión, ya que, al no haber alcanzado el punto de gresificación, se deshace y el asta produce el redondeamiento de los filos evitando el agarre del percutor al nódulo. Para conseguir resultados positivos, el tallador debe aumentar la velocidad del golpe.

El nódulo 4 alcanzó un punto de cocción en el que la abrasión era posible pero no totalmente satisfactoria. 
Sin embargo, el nódulo 2 sí permite la abrasión sin deshacer los filos al haber alcanzado el punto de gresificación. Su comportamiento es óptimo.
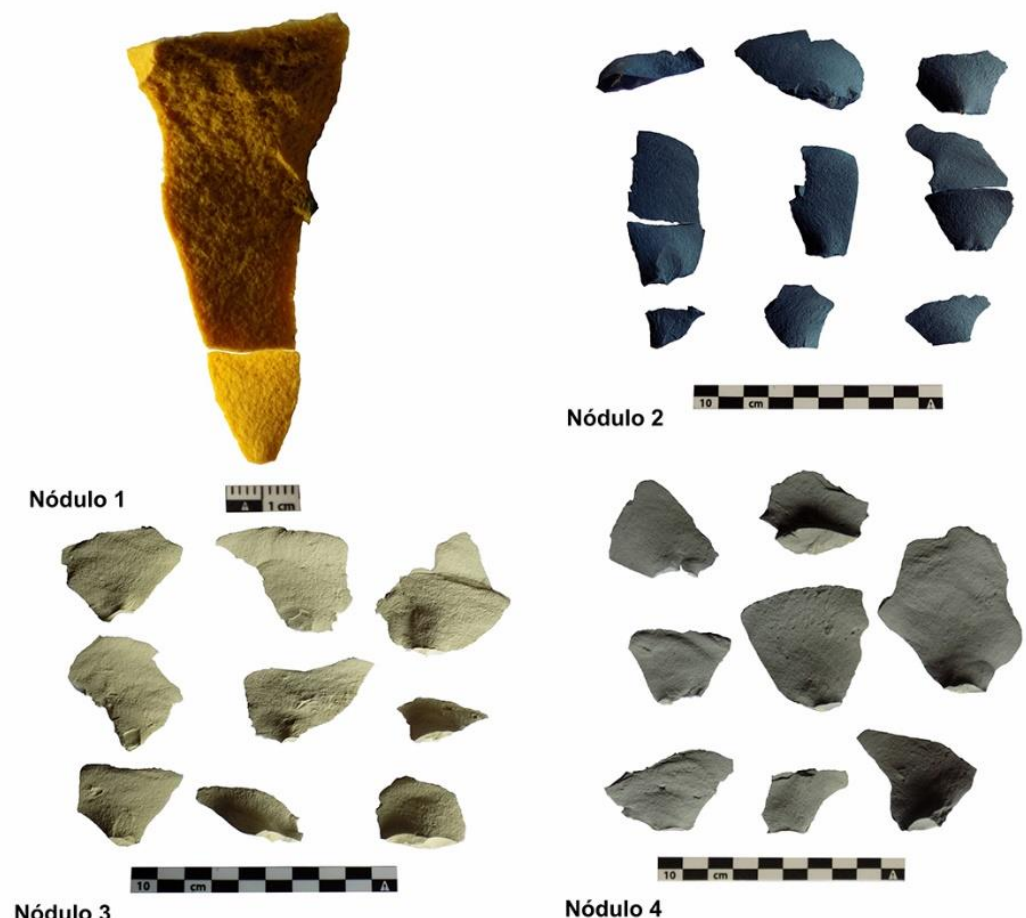

Figura 10: caras ventrales de los productos obtenidos con percutor de boj.
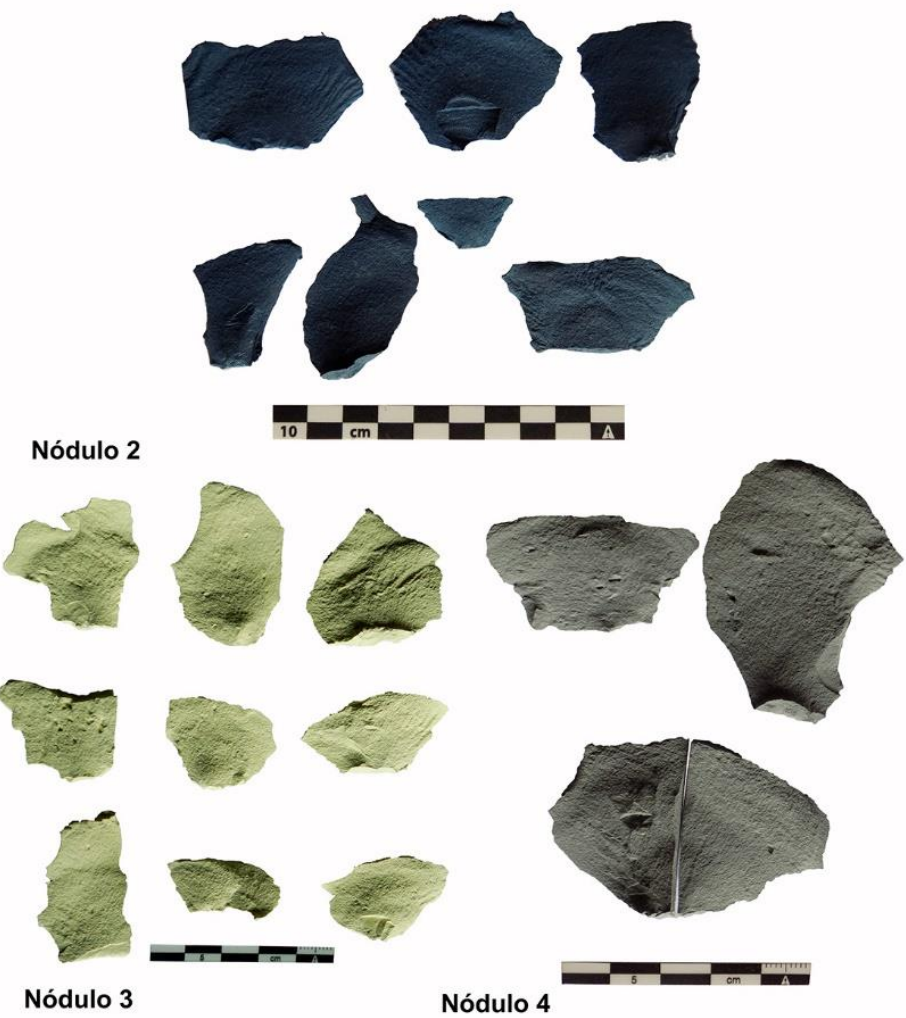

Figura 9: caras ventrales de los productos obtenidos con percutor en asta de alce. 


\subsection{Visibilidad}

El segundo objetivo de este trabajo era comprobar si la visibilidad de los atributos de talla es mejor en colores claros que en oscuros. A este respecto, hay que señalar que todos los núcleos presentan una buena visibilidad, si bien las huellas de los impactos no son apreciables en los nódulos 1 y 3 , de color amarillo. Los impactos quedan bien registrados en los nódulos oscuros, 2 y 4, si bien en el caso del nódulo azul, se observan de forma especialmente buena los impactos realizados con boj y asta, ya que los restos amarillos de los percutores que quedan desprendidos en el nódulo contrastan de forma especialmente óptima en el color azul, al ser complementarios.

En cuanto a los impactos con piedra, los nódulos oscuros ofrecen un buen contraste con la zona del impacto en la que se produce una pequeña "pulverización" de color blanco.

En cuanto a la visibilidad de ondas, estrías y la producción de accidentes, parece buena en los cuatro nódulos. Aun así, en el nódulo 1 no pudo comprobarse del todo por su mayor nivel de fragmentación. En este caso hay que señalar que presentaba zonas de aspecto esponjoso o poroso por cientos de pequeñas burbujas que no favorecen la visibilidad de estigmas sutiles.

Los nódulos óptimos para la visibilidad de atributos son los oscuros (números 2 y 4).

\section{CONCLUSIONES}

Esta no es la primera vez que se sustituyen las rocas por porcelana en experimentos de talla lítica. Sin embargo, la fabricación de nódulos y otros detalles no suelen ser descritos en la literatura.

En este trabajo se han fabricado cuatro nódulos de porcelana en dos tipos de masas diferentes (TecniClay y SAF) con temperaturas de gresificación distintas. El objetivo era probarlos para determinar si su comportamiento ante la percusión directa es similar al de las rocas silíceas y cuál sería un color óptimo para la visibilidad de atributos.

La primera conclusión a extraer de esta experiencia es que es necesario poner mucha atención en cada proceso de fabricación para garantizar el éxito. El amasado debe ser muy cuidadoso, ya que, aunque la aparición de algunas burbujas en los nódulos tallados indica que han aguantado el proceso de cocción, la fracturación de algunas partes sugiere que una sola de esas burbujas puede impedir el trabajo posterior.

Los cuatro nódulos sufrieron una pérdida de peso bastante notable en el proceso de secado entre un 24 y un $28 \%$. Para obtener un nódulo cocido de $1 \mathrm{k}$ de peso como mínimo, que permita la elaboración de objetos de un cierto tamaño, se necesitaría entre 1330 y $1400 \mathrm{~g}$ de masa inicial en húmedo.

Las pruebas efectuadas con percusión directa y percutores minerales y orgánicos han revelado que la porcelana es un material apto que ofrece una tenacidad similar a la de las rocas silíceas y homogeneidad. 

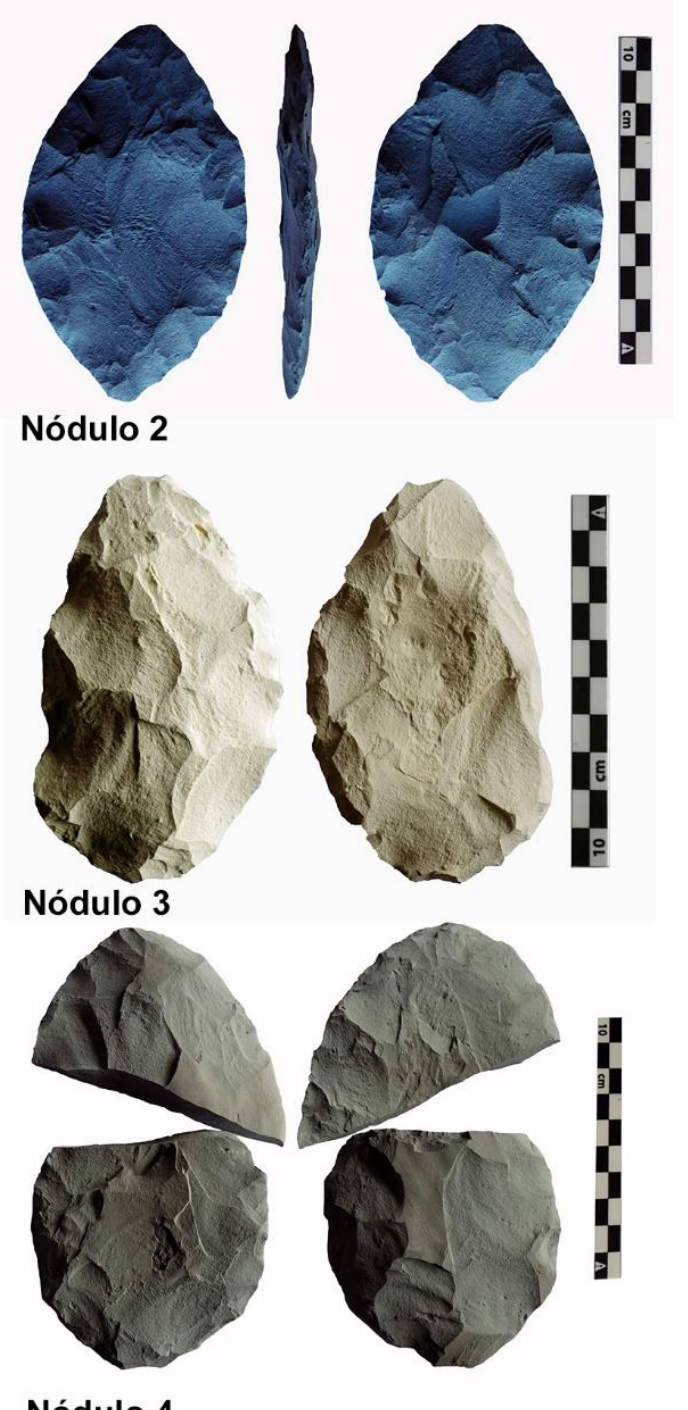

Nódulo 4

Figura 11: aspecto final de los nódulos tallados en forma de foliáceos.

En general, el nódulo con arcilla TecniClay azul que había alcanzado el punto de gresificación (nódulo 2), ha respondido de manera óptima a los cuatro tipos de percutores, siendo el que mejor resultado ha ofrecido ante la abrasión con arenisca previa a la percusión con asta. El nódulo 4, de color gris oscuro, elaborado con porcelana SAF ha respondido de forma similar.

El que dos nódulos con el mismo tipo de masa (3 y 4) respondan de manera diferente habiendo sido sometidos a la misma cocción solamente puede explicarse por la acción de los componentes añadidos responsables del color que parece que están influyendo en el proceso de alguna manera.

En cuanto a la visibilidad de los atributos en este tipo de material, se ha comprobado, tal y como esperábamos al inicio de la experiencia, que los nódulos de color oscuro facilitan la visibilidad tanto de impactos como de ondas y estrías.

La arcilla TecniClay presenta dos ventajas fundamentales sobre la porcelana SAF, además de haber obtenido los mejores resultados en las pruebas realizadas. La primera es que requiere menor temperatura para alcanzar la gresificación y eso permite un ahorro 
energético importante en su fabricación en serie para grandes cantidades. La segunda ventaja es que el precio por kilo es inferior al de la porcelana SAF negra.

Sin embargo, el mayor contenido de agua tiene como consecuencia que sea necesario más masa inicial para obtener los mismos resultados en comparación con la porcelana SAF negra. Como resultado, apenas hay diferencias económicas en el precio de la masa en crudo.

\section{Agradecimientos:}

Este trabajo se realizó gracias a un contrato postdoctoral del Programa de Atracción del Talento Investigador de la Comunidad de Madrid 2017-T2/HUM-3488 y al proyecto PGC2018-093309-A-I00 "Aprendizaje en la Prehistoria" del Programa Estatal de Generación de Conocimiento y Fortalecimiento Científico y Tecnológico del Sistema de I+D+i, cofinanciado por el Ministerio de Ciencia, Innovación y Universidades y el Fondo Europeo de Desarrollo Regional (FEDER).

La autora quiere agradecer al Prof. Javier Baena Preysler, su experiencia y disponibilidad para la talla de los nódulos cocidos y al Laboratorio de Arqueología Experimental de la Universidad Autónoma de Madrid.

\section{Bibliografía}

BAENA, J. y GONZÁLEZ, J. (1998): "Las materias primas". En J. BAENA (coord.). Talla lítica experimental. Introducción a la talla de utillaje prehistórico. BAR International Series, 721: 19-26. Oxford.

COTTERELL, B. (2010): Fracture and Life. Imperial College Press, Londres.

CRABTREE, D. E. (1971): "Notes on Experiments in Flintknapping 3: the flintknappers raw material". En CRABTREE, D. E. Experiments in Flintworking: 8-24. Idaho State University Museum, Pocatello.

DAVIS, A. J. y SHEA, J. J. (1988): "Quantifying Lithic Curation: an Experimental Test of Dibble and Pelcin's Original Flake-Tool Mass Predictor". Journal of Archaeological Science, 25: 603-610.

DIBBLE, H. L. y PELCIN, A. (1995): "The Effect of Hammer Mass and Velocity on Flake Mass". Journal of Archaeological Science, 22: 429-439.

DIBBLE, H. L. y WHITTAKER, J. (1981): "New experimental evidence on the relation between percussion flaking flake variation”. Journal of Archaeological Science, 6: 283296.

Geribàs, N.; Mosquera, M. y Vergès, J. M. (2010): "What Novice Knappers Have to Learn to Become Expert Stone Toolmakers". Journal of Archaeological Science, 37: 2857-2870

HARWOOD, R. y CRANDELL, O. (2010): "Practical Applications of Dekton Artificial Rock for Experimental Archaeology and Traditional Lithic Technology”. [Online]. Puget Sound Knappers http://pugetsoundknappers.com/interesting_stuff/Dekton.html. [Último acceso 15/03/2019] 
KHREISHEH, N. N.; DAVIES, D. y BRADLEY, B. A. (2013): "Extending experimental control: the use of porcelain in flaked stone experimentation". Advances in Archaeological Practice, 1(1): 38-46.

ROY, B. (2009): "Prehistoric sites in Mandla, Madhya Pradesh (India), with evidence of using modern materials". Hukay, 14: 25-46.

SPETH, J. (1972): "Mechanical basis of percussion flaking". American Antiquity, 37: 3460.

WHITTAKER, J. C. (1994): "Flintknapping: Making and Understanding Stone Tools". University of Texas Press, Austin.

WHITTAKER, J. y STAFFORD, M. (1999): "Replicas, Fakes, and Art: the Twentieth Century Stone Age and its Effects on Archaeology". American Antiquity, 64(2): 203-214. 